\title{
OBSERVAÇÕES COTIDIANAS DE UM GATO INTELECTUAL
}

Celia Tamura ${ }^{\prime}$

ABstract: This paper analyzes the roles of riempitivi and digressions in the Natsume Sōseki's novel Wagahai wa neko de aru (I am a cat, 1906) considered a typical $19^{\text {th }}$ Century novel, which the Author created basing on English literary sources, mainly Laurence Sterne's The life and opinions of Tristram Shandy, gentleman (1760-1767). The humor in the Sōseki's novel - expressed in riempitivi and digressions - creates an ironical comedy, which hide a pessimistic and nihilistic conception of life.

Keywords: Wagahai wa neko de aru, Natsume Sōseki, Japonese novel.

O romance Wagahai wa neko de aru (1906), ou Eu sou um gato, ${ }^{2}$ livro de estreia do escritor japonês Natsume Sōseki³ (1867-1916), obteve imediato êxito de crítica e de público, devido à sua prosa ágil, bem-humorada e aparentemente despretensiosa, entremeada de pensamentos filosóficos cosmopolitas, mas que preserva, ao mesmo tempo, um substrato local, peculiarmente japonês. Considerada a primeira obra literária de Sōseki, a despeito de sua prévia obra

1 Doutoranda em Teoria e História Literária, no Instituto de Estudos da Linguagem - Unicamp. O presente trabalho foi realizado com o apoio do Conselho Nacional de Desenvolvimento Científico e Tecnológico - $\mathrm{CNPq}$ - Brasil.

2 O romance conta com a recente tradução, brilhantemente realizada, diretamente do japonês, por Jefferson José Teixeira, publicada pela Editora Estação Liberdade, 2008. As passagens do romance, citadas neste artigo, pertencem à referida tradução.

3 O nome do Autor, Natsume Sōseki, obedece aqui à norma tradicional, em japonês - sobrenome seguido de prenome -, porém, assim como Mori Ōgai, Sōseki é usualmente referido pelo prenome (Sōseki), e não pelo sobrenome (Natsume). 
poética em chinês, japonês e inglês, é vista, por alguns críticos, como a obra-prima do Autor. O romance foi publicado em onze capítulos, no periódico literário Hototogisu, de janeiro de 1905 a agosto de 1906, e contou com a recepção entusiasmada de críticos e leitores, o que possibilitou a sua continuidade, já que a ideia inicial era escrever apenas o texto equivalente ao primeiro capítulo da história do gato. Donald Keene observa que Sōseki escreveu o livro como um meio para escapar ao seu estado depressivo, e que poderia continuar escrevendo por toda a vida ao estilo de Wagahai wa neko de aru, porém seria difícil manter o tom frívolo nos momentos em que era acometido de depressão, mal do qual sofria (KEENE, 1984, p. 314)

Sōseki, grande conhecedor das tradições poéticas japonesa e chinesa, foi também estudioso da literatura europeia, em especial da inglesa, tendo sido 0 segundo homem a se graduar no curso de Literatura Inglesa pela Universidade Imperial de Tóquio, em 1893. Lecionou na Escola Especializada de Tóquio, hoje Universidade Waseda, sucedendo Lafcadio Hearn. Ao ingressar no curso de Literatura Inglesa, Sōseki via com desgosto a civilização ocidental, mas acreditava que o aprendizado da totalidade do mundo era necessário antes que o pensamento moderno e individualista pudesse ser disseminado no Japão (KEENE, 1984, p. 307). Dessa forma, Sōseki analisa o país num período conturbado, em meio às transformações decorrentes da Restauração Meiji, retratando as mudanças sociais em curso, vislumbrando o futuro. Segundo Keene, Sōseki situa seu romance num ponto, o período Meiji, mas, como bom oriental, sempre traz em mente a tradição e o passado. Mas, como um profeta, vislumbra o que está por vir, identificando as tendências da sociedade. Sua obra retrata o ser humano e seus preconceitos antigos, com a necessidade de se adaptar aos novos tempos, e a perplexidade que essa transformação acarreta. $O$ contato com a mudança impõe uma decisão, de integração às novas normas, às novas práticas sociais. Porém, o ser humano, com sua integridade partida, ainda mantém algo que escapou à desintegração, explica Keene.

Etō Jun, citado por Keene, crê ser a ausência de forma do livro indicativa da situação moderna da sociedade japonesa, bem como ilustrativa da confusão entre os intelectuais. Apesar da boa recepção de Wagahai wa neko de aru pela maioria dos leitores, alguns escritores naturalistas consideraram que Sōseki 
não tinha nada mais profundo em mente senão entreter o público com um humor superficial ao estilo haika. (KEENE, 1984, p. 314). Mas é preciso concordar com a opinião do crítico Itō Sei (1905-1969), para quem o romance possui uma coerência que acompanha a história narrada, do início ao fim.

Bem ao gosto burguês, Wagahai wa neko de aru entretém, em sua totalidade, com sua leveza e seu humor. Mas essa aparente despretensão oculta uma mensagem bastante séria, pessimista. Por trás do humor e da comicidade, insinua-se o desespero humano diante da fatalidade da vida. Em seu niilismo, Sōseki encara a morte como uma fuga da vida, a única forma de alcançar a tranquilidade. "Morrer é doloroso, mas ainda mais doloroso é não poder morrer. Para um povo neurastênico viver é uma experiência ainda mais dura do que morrer." (NATSUME, 2008, p. 463) Para Sōseki, os avanços sociais e culturais acarretarão, certamente, um sufocamento para o ser humano, tornando-lhe a vida insuportável.

Itō Sei comenta que Sōseki, desde o tempo de estudante, era hábil conversador, apreciava o humor e era amante de anedotas. Em sua estada em Londres, por dois anos, como bolsista do Ministério da Educação, Sōseki dedicou-se exaustivamente à leitura de autores ingleses, dos quais os seus preferidos eram George Meredith (1828-1909), de quem apreciava o humor, e Charles Dickens, que apresentava as lágrimas e os risos dos desvalidos. No romance Wagahai wa neko de aru, há ampla citação de autores estrangeiros, como Sterne, Thackeray e Carlyle; filósofos e poetas gregos, chineses e japoneses, como Masaoka Shiki - amigo pessoal de Sōseki, Ryōta Oshima e muitos outros. O círculo de intelectuais que frequentam a casa do professor Kushami é versado em literatura ocidental, sempre discutindo acerca de obras poéticas, escritores e críticos literários japoneses e estrangeiros.

No entanto, a mera identificação entre Sōseki e a figura caricata de Kushami equivale a uma generalização por demais simplificada. A opinião, praticamente unânime, de que Sōseki tem em Kushami seu alter ego constitui uma afirmação superficial e simplificadora. Cada personagem traz um pouco de Sōseki, como o conversador Meitei e o religioso Dokusen, assim como o próprio gato, mais particularmente. Donald Keene observa que o título pomposo wagahai usado para "Eu", referindo-se a um simples gato, estabelece o tom da obra, escrita à maneira dos narradores do período Edo. 
Fatos diversos compõem o romance, acontecimentos de pequena importância, como no romance de Laurence Sterne, $A$ vida e as opiniões do cavalhei. ro Tristram Shandy, obra sobre a qual Sōseki publicou uma crítica em 1898. Wagahai wa neko de aru alonga-se em detalhes variados, que ampliam a narrativa e ao mesmo tempo proporcionam a ela leveza de tom. A concentração em pormenores, na maioria das vezes desnecessários, caracteriza o romance burguês, que teve seu auge no século XIX.

A extensão da narrativa, privilegiando os pormenores desnecessários riempitivi ${ }^{4}$ - que compõem o relato bem-humorado, centra-se nas conversas cotidianas da vida doméstica de Kushami e seus amigos. Embora cada detalhe contribua para a obtenção de uma caracterização mais completa das personagens, a repetição torna a narrativa redundante, sendo nessa constante reiteração que reside o humor, como se o gato narrador atraísse o leitor para uma armadilha, rindo-se, ele também, de quem o lê. Os motivos livres, em sua repetição constante, marcam a comicidade, sem dispersar, porém, o interesse do leitor, por seu extremo poder de entretenimento bem-humorado. Enfim, o que poderia ser excluído da narrativa torna-se o elemento portador de maior comicidade. O que anteriormente costumava ser ocultado das narrações de romances, por serem detalhes destituídos de importância, passa a ser exibido: os costumes domésticos, como comer, dormir, os hábitos de higiene, as conversas diárias.

$\mathrm{O}$ crítico italiano Franco Moretti caracteriza os riempitivi romanescos como aqueles episódios em que não sucede um grande fato, e dos quais se recorda muito pouco, depois de finda a leitura. Essa técnica consiste num dos grandes valores do século XIX: a impessoalidade, a precisão, a conduta de vida regular e metódica, um certo destaque emotivo; em uma palavra, a "seriedade". Enfim, a seriedade burguesa, na França, na Grã-Bretanha e na Alemanha (MORETTI, 2001, p. 689). O riempitivo elabora uma descrição do mundo observado, na tradição pictórica holandesa, uma arte descritiva, e não mais narrativa, que pode ser bem exemplificada pela pintura de Vermeer, explica Moretti, citando a observação de Svetlana Alpers (MORETTI, 2001, p. 689).

4 O termo italiano riempitivo pode ser traduzido para o português como "preenchimento". 
O tom sério, contudo, será confrontado e ridicularizado, na obra de Laurence Sterne, $A$ vida e as opiniões do cavalheiro Tristram Shandy, que abusa, de maneira extrema, do recurso de riempitivi. À pergunta "o que significa, afinal, sério, em literatura?” Moretti responde citando Diderot, para quem o sério equivale a uma forma situada em posição intermediária entre tragédia e comédia. Efetivamente, com o advento do ethos sério, e a paralela multiplicação dos riempitivi, o romance ganha um ritmo novo, tranquilo, um tipo de "neutralidade" narrativa. Tanto se escreve como se lê com um espírito novo, prosaico, que não espera coisa inaudita ao se virar a página. Basta que a história seja "interessante", para citar uma outra categoria dos Entretiens (MORETTI, 2001, p. 694). O riempitivo é, em suma, uma tentativa de racionalizar o romance, bem como de desencantar o seu universo narrativo: pouca surpresa, menos aventura, e tampouco milagres a serem narrados. O riempitivo transmite a lógica da racionalização que investe a própria forma do romance, seu ritmo narrativo (MORETTI, 2001, p. 708).

Como explica Moretti, a narrativa, em geral, não é feita apenas de grandes cenas; há as cenas cotidianas, nas quais se fazem as refeições, jogam-se cartas, faz-se um passeio, ouve-se música, conversa-se, recebem-se correspondências, bebe-se um copo de vinho ou uma xícara de chá, por exemplo. A narração existe, mas refere-se ao cotidiano. Tais narrações são os riempitivi. Os riempitivi mantêm o narrado dentro do ordinário da vida. Graças a isso, a vida cotidiana torna-se elevada, estilizada: é uma meia comédia, e se enche de dignidade (MORETTI, 2001, p. 691).

Segundo Ian Watt, a atenção aos detalhes da vida cotidiana pode ser classificada, ainda, como uma das características do realismo. ${ }^{5} \mathrm{O}$ romance burguês,

Conforme observa Ian Watt, os historiadores do romance consideraram o "realismo" a diferença essencial entre a obra dos romancistas do início do século XVIII e a ficção anterior. Dessa forma, o fabliou e a picaresca são "realistas" porque, ao apresentar o comportamento humano, privilegiam motivos econômicos ou carnais (WATT, 1990, p. 12). Segundo Watt, o romance não constitui simplesmente o retrato do lado feio da existência, mas sim procura retratar todo tipo de experiência humana e não só as que se prestam a determinada perspectiva literária: o realismo não está na espécie de vida apresentada, e sim na maneira como a apresenta, explica Watt. Quanto a essa questão, Watt cita Lord Kames, em seus Elements of criticism (1762), no qual se declara 
em sua forma genérica, procurava rebaixar o nível literário a fim de atender às expectativas do público leitor, que em geral procurava nos romances fantasia e sentimentalismo. Entretanto, Sterne foi um dos romancistas que se destacaram, pela qualidade de sua obra, $A$ vida $e$ as opiniões do cavalheiro Tristram Shandy (1760-1767). Sua originalidade literária confere à obra uma característica muito pessoal e excêntrica, apresentando boas soluções para os grandes problemas formais levantados por seus predecessores. Por um lado, Sterne encontrou um modo de conciliar o realismo de apresentação de Richardson com o realismo de avaliação de Fielding e, por outro lado, mostrou que não havia um antagonismo necessário entre os enfoques respectivamente interior e exterior com que abordaram as personagens (WATT, 1990, p. 252-3). Watt classifica o romance de Sterne como uma paródia de romance, que volta sua ironia contra muitos métodos narrativos do novo gênero.

José Paulo Paes define o romance de Sterne como "supremo monumento à irregularidade cujo primo mobile parece ser o horror à linha reta e a paixão pelo labirinto" (PAES, 2008, p. 19), sendo que os interlúdios de seriedade, por bem dosados, não chegam a perturbar o livre fluxo da veia cômica (PAES, 2008, p. 30). A digressão é um artifício deliberadamente utilizado no Tristram Shandy para desviar o foco de interesse, dos sucessos em si para a maneira por que são narrados. ${ }^{6}$

O romance Wagahai wa neko de aru prossegue entrelaçando fatos engraçados, construindo, dessa forma, um enredo coerente, a despeito da lentidão da narrativa. O romance guarda o humor e a novidade, o frescor, ainda atualmente, um século depois de sua primeira publicação. O traço de época é dado pela apresentação do meio de transporte, o riquixá, além das vestimentas

que "termos abstratos ou gerais não produzem bons resultados numa composição destinada à distração; porque é somente com objetos particulares que as imagens podem se formar" (WATT, 1990, p. 18).

6 José Paulo Paes observa que, na exuberância digressiva de Sterne, havia, igualmente, um propósito de crítica ao romance de sua época, explicitada na passagem em que ele impõe uma penitência à sua leitora, pelo "gosto viciado em que se comprazem milhares de pessoas além dela - de ler sempre em linha reta, mais à cata de aventuras que da profunda erudição e saber que um livro desta natureza, quando lido como deve, infalivelmente lhes proporcionará" (PAES, 2008, p. 33). 
características do Japão do período Meiji, bem como as constantes referências a esse momento histórico.

O encontro de personagens e a conversa entre elas correspondem ao assunto principal da narrativa. Sendo assim, o que se privilegia é a descrição, mais que a narração. A leitura fluente não deixa de apresentar, porém, as dimensões ideológicas do livro. O crítico Itō Sei destaca a forte crítica à sociedade japonesa, considerando Sōseki o escritor que, entre seus contemporâneos, mais soube criticar a si mesmo, rindo-se da sociedade e condenando-a de modo amargo (ITŌ, 1995, p. 492).

No romance, a personalidade do gato é coerente com o fato de ele ser um felino, com ronronares, miados, gosto por comida e pelo sono, e até mesmo em seus esportes, como caça aos louva-a-deus e captura de cigarras. Suas ações são descritas como numa história em quadrinhos, combinando, ao mesmo tempo, características físicas animais e inteligência humana. Um animal falante, que fala apenas aos leitores e aos outros gatos, assemelha-se a uma personagem de desenho animado moderno. Com sua observação arguta consegue identificar as diferenças entre felinos e humanos, demonstrando grandes estranhamentos. Nascido gato, vai-se humanizando, ao longo de seus dois anos de vida. Em sua condição de animal, o gato é um ser situado à parte da sociedade, a exemplo dos típicos intelectuais do período Meiji, como o professor Kushami. Como animal, não tem pudores, censuras, impedimentos ou inibições para zombar, usando de todo o seu sarcasmo. O gato se faz presente nas cenas, ao mesmo tempo em que está de fora, como mero observador, sendo um animal, sem maiores interações com os humanos.

O tom humorístico vem da própria voz narrativa. Usando de um tom jocoso, em suas observações sagazes, o felino realiza a crítica dos valores aceitos pela sociedade. "Os gatos também riem. Os humanos se enganam ao acreditar serem as únicas criaturas capazes de sorrir. Quando eu rio, minhas narinas tomam o formato triangular e meu pomo-de-adão vibra, algo imperceptível para os humanos" (NATSUME, 2008, p. 47). Zomba das características físicas das pessoas, reparando em cada detalhe, sarcasticamente. Elucida circunstâncias, por sua capacidade de se movimentar agilmente, penetrando nas casas de pessoas da vizinhança, sem ser notado. Histórias externas ao círculo familiar 
são contadas na narrativa, aproximando-a, por vezes, da rapsódia. O gato intelectual expõe suas opiniões, revelando-se um alter ego do autor, ao lado do professor Kushami. Este é descrito como um estorvo à sociedade, não se ade. quando às regras sociais. Mas não só ele é assim: o gato também representa um incômodo para os membros da família com que mora. Ele também é ridicularizado por todos, chamado de "gato estúpido" a todo momento. Como Sōseki, que foi adotado por uma família, o gato sem nome mora com um amo que o acolheu, já que não possui um lar de nascimento. A esse amo, dedica obediência, em troca de lar e comida, embora seja maltratado com frequência, fato de que se queixa em seus relatos.

O professor e o gato representam personalidades complementares, já que o animal adquire muitas das características do dono. Zombam um do outro. 0 dom da telepatia é o recurso ideal encontrado para o narrador onisciente, que apresenta os fatos observados, além de perscrutar a mente das personagens. O gato vira-lata pode penetrar nas casas das pessoas, e relatar as conversas ouvidas aos leitores. Mas a característica felina vai-se perdendo, aos poucos, dando-se maior destaque aos acontecimentos entre as pessoas, a partir da segunda metade do romance. Ainda no início, há maior caracterização animal, quando o gato narra suas amizades com Kuro, o gato do puxador de riquixá, $e$ Mikeko, a bela gatinha da professora de koto. Após a morte de Mikeko e a decadência física de Kuro, o gato sem nome passa a conviver exclusivamente com humanos, adquirindo cada vez mais as características destes. Passa a observar as ações do círculo de intelectuais que frequenta a casa de Kushami. "Agora que estou me tornando um humano, sinto dificuldades em continuar observando o comportamento dos gatos com os quais não mais convivo. Portanto, tomarel a liberdade de tecer comentários sobre Meitei, Kangetsu e outros professores" (NATSUME, 2008, p. 90). Anteriormente, porém, o gato sentia dificuldades em compreender as motivações humanas, experimentando estranhamentos a cada movimento testemunhado.

Como o gato, Kushami mantém-se à distância dos fatos, dos acontecimentos sociais e familiares. Traça-se um perfil claro e marcante da personalidade do Professor, por meio de pequenos detalhes e acontecimentos banais. "Todavia, meu amo não é de forma nenhuma um homem de mau caráter. Seria maja 
correto dizer que não é o tipo de homem com inteligência desenvolvida o suficiente para fazer de si um homem mau" (NATSUME, 2008, p. 308). O professor Kushami, apesar de sua mediocridade, de sua comicidade e de sua indiferença, age de forma íntegra, se comparado às outras pessoas. Dessa forma, a covardia de Kushami converte-se em sua maior virtude. $\mathrm{O}$ gato, afeiçoado ao dono, demonstra apego à sua casa, da mesma forma que ao seu país. "O aluguel da casa de meu amo pode ser baixo, mas é nela que mora o professor Kushami" (NATSUME, 2008, p. 289). A cerca preta de bambu, caindo aos pedaços, e as ervas daninhas crescendo no telhado revelam uma vida pobre e desleixada, mantida com o salário de professor.

A profissão de docente é ridicularizada despudoradamente, chegando-se a comentar que até mesmo um gato poderia exercer essa atividade. "Se é possível dormir tanto nessa profissão, é sinal de que até mesmo um gato pode exercê-la. Apesar disso, meu amo diz que não há profissão mais árdua do que a de um docente, e costuma se queixar dela a todos os amigos que o visitam" (NATSUME, 2008, p. 14).

O gato detém-se na explicação da arte de caçoar, bem como em suas regras, expondo um tratado, elaborado a partir de suas observações. $\mathrm{O}$ bichano equipara os macacos do zoológico de Asakusa aos professores, classificando-os como as categorias mais fáceis de serem caçoadas. "É uma afronta comparar símios a professores. Uma afronta não para os símios, mas para os professores, obviamente. Porém, que posso fazer se eles são tão semelhantes?, questiona o gato (NATSUME, 2008, p. 295).

A comicidade gratuita, na maior parte das vezes, provém dos relatos de maus tratos sofridos pelo gato, dos quais se encarregava primeiramente pela empregada Osan, que o expulsa da cozinha, indefinidamente; depois o próprio professor, de quem o gato leva pancadas de régua, ao se aproximar da cama das crianças. O bichano é bastante ridicularizado pelos moradores da casa, principalmente quando tenta comer um pedaço de mochi (bolinho de arroz), acaba com os dentes grudados e, não conseguindo soltá-los, executa uma dança patética.

As observações acerca das peculiaridades dos humanos giram em torno dos assuntos mais prosaicos, sobretudo os cabelos, os narizes, os alimentos e as 
vestimentas. Na opinião do gato, os humanos deveriam permitir que os cabelos crescessem com naturalidade, à revelia, para poupar trabalho. "No dia em que nós felinos inventarmos vinte maneiras diferentes de cortar nossos pelos, certamente nossa tranquilidade acabará” (NATSUME, 2008, p. 213).

A referência aos cabelos é constante, ao longo da narrativa, já que os fios capilares representam um dos principais pontos em que se foca a vaidade humana. Portanto, as pessoas dedicam grande parte de seus esforços para arrumá-los, embelezá-los, embora não sejam de importância vital. O professor Kushami critica a calva no topo da cabeça da esposa, o que causa a irritação desta. Meitei conta a história de seu amor infeliz por uma bela moça, moradora das montanhas, que tinha o hábito de comer risoto de cobras. Conhecendo-a uma noite, pela manhã descobre que era calva. Meitei atribui a calvície à ingestão de carne de cobra, que ativaria a circulação sanguínea da região capilar. 0 gato tece uma reflexão acerca da calvície dos intelectuais, exemplificando com o caso de Ésquilo.

$\mathrm{Na}$ luta quixotesca contra o exército formado pelos ratos da cozinha da casa, a exemplo da guerra russo-japonesa, o gato empenha-se em combater o batalhão de ratos, não obtendo sucesso, porém. "Parece que já há algum tempo o Japão trava uma enorme guerra contra a Rússia. Como eu sou um gato japonês, obviamente torço pela vitória de meu país" (NATSUME, 2008, p. 202). A imagem do cenário ao fundo é bela e poética, com flores de cerejeira e luar, compondo um ambiente épico, heroico. "Como ontem, o sol de primavera se pôs e pétalas de flores de cerejeira, embaladas por uma brisa ocasional, entram pela abertura no papel de arroz da porta corrediça. Flutuando dentro de um balde d'água, elas brilham sob a luz fraca da lâmpada da cozinhil" (NATSUME, 2008, p. 203). O gato imagina-se um almirante Togo felino. Como animal, não possui vergonha de assumir e expor suas experiências ridít culas. O amo assusta-se com o barulho, pensando ser um ladrão o causialdor dil barulheira. "A lua se deslocava em direção ao oeste, e o facho branco de luz qul" banhava a cozinha se tornava mais estreito" (NATSUME, 2008, p. 210). O $\mathrm{Ce}^{2}$ nário belo e grandioso, contrastando com a ação ridícula da batalha, ilustrith ironicamente, o lirismo do gato. O elemento poético, composto pela claridadé da lua e por pétalas de flores de cerejeira, contrasta com o local prosaico. A 
beleza da natureza confronta-se com a materialidade da cozinha, compondo um misto de sublime e prosaico.

Por meio das digressões, o bichano caçoa da curiosidade do leitor. No episódio do ladrão, por exemplo, a história é suspensa, a fim de que se possam tecer reflexões filosóficas acerca dos rostos humanos e do Deus que os criou. Mais que indiferença ou impassibilidade, o felino demonstra sua impotência diante da situação de roubo. A narrativa interessante, acerca da identidade do ladrão, assim como das ações que viriam a ocorrer, é interrompida, e passa-se a falar de algo paralelo, alheio ao assunto narrado até então. "Pela ordem desta narração, esta é a hora em que eu terei a honra de apresentar aos leitores este inesperado e raro visitante, mas antes disso pediria alguns instantes de sua atenção para expor minha humilde opinião" (NATSUME, 2008, p. 182). Da mesma forma, quando Meitei narra o caso do vendedor de meninas, tende a se dispersar para outro assunto, referente a uma loja de tecidos, pelo que é repreendido: “ - Afinal de contas, você está contando sobre a loja de tecidos ou sobre o vendedor ambulante de meninas?" (NATSUME, 2008, p. 235). Há um adiamento da narrativa, com o acréscimo da curiosidade, mantendo o leitor na expectativa, como se o narrador risse do leitor, ao pregar-lhe uma peça. As divagações, com mudanças de assuntos ao sabor das oportunidades, conduzem os temas das narrações ao acaso, imprimindo-se um movimento tortuoso às conversas, que não se centram num ponto específico, perdendo-se o foco frequentemente.

O pessimismo do gato passa a ser revelado em diversas passagens, na parte final do romance. "Embora desprezível, ao nascer no mundo dos humanos é preciso não apenas se resignar quando se é pisoteado, chutado, surrado ou desprezado, como também tirar prazer em ser objeto de zombarias ao ser cuspido ou coberto de excrementos" (NATSUME, 2008, p. 412). Por ter experimentado a sufocação, ao ser preso dentro do aquecedor, o gato teme a morte, instintivamente. Porém, o mesmo gato que abominava a ideia de trocar de lugar com a amada Mikeko, quando da morte desta, passa a ter uma visão inversa acerca do mundo: "Se não tomarmos cuidado, nós gatos também seremos obrigados a nascer neste mundo sufocante. Isso será terrível. Sinto-me deprimido. Decido beber a cerveja de Sampei para me animar um pouco" (NATSUME, 2008, p. 483). 
O gato sem nome, ao ir assimilando as características da personalidade de seu amo, deseja participar das mesmas experiências dos humanos, como ir ao banho público, por exemplo. Até que, ao final, decide provar a bebida alcoólica, tão apreciada pelo professor e seus amigos. É o estágio final da humanização. A embriaguez causa a morte do gato. Para os humanos não há esperança, assim como para um gato que se aproxime do caráter dos humanos. Revela-se, aí, todo o niilismo de Sōseki, a despeito da comicidade que predomina em todo o romance. Que não se engane o leitor com o humor de Sōseki, pois este se revela um disfarce de todo o desespero e negatividade do Autor.

\section{Referências bibliográficas}

ITŌ, S. Kaisetsu. In: Wagahai wa neko de aru. Tóquio: Shinchōsha, 1995.

KEENE, D. Dawn to the west: Japanese literature of modern era; fiction. New York: H. R. and Winston, 1984.

MORETTI, F. Il secolo serio. In: MORETTI, Franco (Org.). Il romanzo. La cultura del romanzo. Vol I. Turim: Einaudi, 2001, p. 689-725.

NATSUME, S. Wagahai wa neko de aru. Tóquio: Shinchōsha, 1995.

2008.

PAES, J. P. "Sterne ou o horror à linha reta". In: STERNE, L. A vida e as opiniões do cavalheiro Tristram Shandy. Trad. José Paulo Paes. São Paulo: Companhia das Letras, 1998. $2^{\text {a }}$ reimpressão, 2008.

STERNE, L. A vida e as opiniões do cavalheiro Tristram Shandy. Trad. e prefácio de José Paulo Paes. São Paulo: Companhia das Letras, 1998. 2ª reimpressão, 2008.

WATT, I. A ascensão do romance. Trad. Hildegard Feist. São Paulo: Companhia das Letras, 1990. 